\title{
Unidirectional independence and judgmental heuristics
}

\author{
IRWIN D. NAHINSKY and DANIEL ASH \\ University of Louisville, Louisville, Kentucky
}

\begin{abstract}
Twenty-eight subjects, trained in basic probability, were asked to judge the likelihood of one trait (A) given another trait (B), as well as the likelihood of Trait B given Trait A. Judgments were made relative to the base rate of the trait whose conditional probability was to be judged. A substantial proportion of paired judgments $(.21)$ were of the form $p(A \mid B)=p(A)$ and $p(B \mid A)$ $\neq p(B)$, a relationship that violates the product rule for independent events. We concluded that estimates were made on the basis of some judgmental heuristic that did not include application of probabilistic reasoning. Alternatives, such as Tversky's (1977) model for similarity judgments, were considered.
\end{abstract}

Recent investigations have revealed that individuals have great difficulty in judging probabilities in a manner consistent with the laws of probability (see, e.g., Shweder, 1977; Tversky \& Kahneman, 1973, 1983). Such difficulty has been attributed to the inappropriate substitution of judgmental heuristics for the laws of probability. A judgmental heuristic may be defined as a strategy that relies on natural assessment to produce an estimate or prediction. The use of certain heuristics may interfere with a proper conceptualization of correlation between two events.

A fundamental identity in probability specifies the relationship of independence between two events: if $p(A \mid B)$ $=p(A)$, then $p(B \mid A)=p(B)$, a relationship that follows from the product rule defining the joint probability of two independent events. Furthermore, it is easily shown that if $\mathrm{p}(\mathrm{A} \mid \mathrm{B})>\mathrm{p}(\mathrm{A})$ then $\mathrm{p}(\mathrm{B} \mid \mathrm{A})>\mathrm{p}(\mathrm{B})$. Thus, independence and direction of probabilistic implication are symmetrical relationships.

It is possible that judgmental heuristics could interfere with appropriate application of the aforementioned rules. Shweder (1977) has pointed out that individuals judge personality traits in terms of stereotypical conceptual linkages rather than as characteristics that exhibit observable correlations. Thus, conceptual similarity may be substituted for application of concepts of probability in judging probabilistic relationships. Tversky (1977) has shown that similarity judgments may show asymmetries related to differences between paired objects in feature sets. Thus, individuals are more likely to judge Korea as similar to China than to make the converse judgment. In the former judgment, the overlap of features common to the two countries is assumed to be large relative to the total set of features of the less prominent subject, Korea. In con-

Address reprint requests to: I. D. Nahinsky, Department of Psychology, University of Louisville, Louisville, KY 40292. trast, when China is the subject of the comparison, the overlapping features have less relative weight than in the first judgment according to a model based on common and distinctive features. Such a comparison process applied to probability judgments could result in asymmetrical anomalies in estimates of conditional probabilities.

Confusion of correlation with casuality could also be associated with incorrect interpretation of relationships between two events. Insofar as A is perceived as having a causal impact on $B, p(B \mid A)$ may be judged greater than $p(B)$. However, $p(A \mid B)$ may be judged equal to $p(A)$ if no causal impact of $B$ upon $A$ is perceived.

The questionnaire used in this experiment was modeled after an investigation of probabilistic implication by Hays (1958). He asked subjects to judge the likelihood that an individual would possess a given trait (e.g., "warmth") given that he/she had another trait (e.g., "intelligence"). Hays scaled traits for implicational dominance, as measured by the extent to which presence of a trait increased the estimated probability of other traits. The questions included some of the scaled traits as well as demographic characteristics chosen by the experimenters. A sample of individuals trained in basic concepts of probability were surveyed to determine whether strategies were used that interfered with the correct application of the concepts they had learned.

\section{METHOD}

\section{Instrument}

Each subject was administered a 16-item questionnaire. In each question it was assumed that an individual was drawn randomly from a designated population and possessed an indicated characteristic. The following exemplifies the questions used:

The person drawn from the general population is warm. He/she is

$\begin{array}{lll}\text { Less } & \text { No more nor } & \text { More } \\ \text { likely } & \text { less likely } & \text { likely }\end{array}$

to be submissive than people in general. 
Table 1

Attribute Pairs Used in the Questionnaire

\begin{tabular}{ll}
\multicolumn{1}{c}{$\begin{array}{c}\text { Pairs with Values } \\
\text { Scaled by Hays* }\end{array}$} & $\begin{array}{c}\text { Pairs with Values Chosen } \\
\text { by the Experimenters }\end{array}$ \\
\hline $\begin{array}{l}\text { Submissive-Warm } \\
\text { Intelligent-Submissive }\end{array}$ & $\begin{array}{l}\text { Good athlete-Good student } \\
\text { Good student-Liberal } \\
\text { Intelligent-Warm } \\
\text { Intelligent-Generous }\end{array}$ \\
Generous-Warm & Liberal-Social worker \\
\end{tabular}

*Order of weightings for traits: generous $>$ warm $>$ intelligent $>$ submissive, where $p(A \mid B)>p(B \mid A)$ for Trait $A$ weighted greater than Trait $B$.

Each question was paired with a complimentary question in which two descriptive characteristics, such as "warm" and "submissive," were reversed in position. Four such pairs had pair members juxtaposed in item positions 2 and 3,5 and 6,8 and 9 , and 13 and 14 . Two forms of the questionnaire were constructed so that sets of four different pairs were juxtaposed on each form as indicated.

Table 1 indicates the attribute pairings used in the questionnaire. As the table shows, five of the items included attributes scaled by Hays (1958) for probabilistic implication. The remaining three items included attributes selected by the experimenters. The good student-good athlete pair and the good student-liberal pair referred to a college population, while the remaining pairs referred to the general population.

\section{Subjects and Design}

Two groups of subjects were drawn. One group consisted of 12 psychology graduate students in an advanced statistics course at the University of Louisville. The other group consisted of 16 students in a senior college course in statistics and experimental method at the same university. Half of the subjects in each group were given one form of the questionnaire, and the other half were given the other form.

\section{RESULTS}

Neither the two groups nor the two forms produced patterns of results that showed appreciable differences. Consequently, data were pooled for these two variables in the analyses. Judgment pairs inconsistent with the symmetry requirements of independence and dependence were produced by 22 of the 28 subjects. The range of the number of such errors was $0-4$ with $\bar{x}=1.68$. Judgments for pairs in which the two questions were juxtaposed ("transparent judgments"') did not result in a significantly different number of errors than did judgments for pairs in which the two questions were separated ("remote pairs") [t(27) $=.16, \overline{\mathrm{x}}$ (transparent) $=.82$ and $\overline{\mathrm{x}}($ remote $)=.86]$. Since juxtaposition should have maximized perception of a pos- sible inconsistency, results suggest that subjects were not attempting to reconcile judgments with requirements of rules of probability.

A hypothesis to consider is that a random pattern of responding accounts for the results. Table 2 is a contingency table showing the relationship between responses to the first pair member, $\mathrm{p}(\mathrm{A} \mid \mathrm{B})$, and the second pair member, $p(B \mid A)$. If the second response was made independently of the first response for each pair, the expected number of response agreements for a subject is 3.78 , assuming marginal proportions in Table 2 . All 28 subjects had a larger number of agreements than expected by random response, $\bar{x}=6.32$. The associated sign test was significant, $z=5.60, p<.001$. Thus, the significant between-pair contingency indicates that responses were based on a perceived correlational structure. It is also clear that the structure involved a positive correlation consistent with the correct relationship that $\mathrm{p}(\mathrm{A} \mid \mathrm{B})>\mathrm{p}(\mathrm{A})$ and $\mathrm{p}(\mathrm{B} \mid \mathrm{A})>\mathrm{p}(\mathrm{B})$ are mutually implied. In only one instance was a negative correlation found, that is, $\mathrm{p}(\mathrm{A} \mid \mathrm{B})>\mathrm{p}(\mathrm{A})$ and $\mathrm{p}(\mathrm{B} \mid \mathrm{A})<\mathrm{p}(\mathrm{B})$. Nonetheless, the 47 inconsistent asymmetries indicated that the perceived structure was not bound by the rules of probability.

The distribution of inconsistencies did not quite deviate significantly from equality among the eight attribute pairs $\left[\chi^{2}(7)=12.40, .05<\mathrm{p}<.10\right]$. The good athlete-good student pair and the liberal-social worker pair showed the most frequent asymmetries with 10 each. In 8 of 10 cases, $p$ (liberal|social worker) was estimated to be greater than $\mathrm{p}$ (liberal), while $\mathrm{p}$ (social worker|liberal) was judged equal to $p$ (social worker). The remaining two cases showed the converse asymmetry. A two-tailed sign test for significance of the dominant asymmetry was significant at the .02 level. The asymmetry, $p$ (good student $/$ good athlete $)<\mathrm{p}$ (good student) and $\mathrm{p}$ (good athlete $\mid$ good student $)=p($ good athlete $)$, was favored in 7 of 10 for that pairing. The result was just short of significance by sign test.

The four traits scaled by Hays were examined for degree of implicational dominance. For inconsistent asymmetries, Trait $A$ was scored 1 if $p(B \mid A)>p(B), 0$ if $p(B \mid A)=$ $\mathrm{p}(\mathrm{B})$ and -1 if $\mathrm{p}(\mathrm{B} \mid \mathrm{A})<\mathrm{p}(\mathrm{B})$. The resulting average dominance scores were $.75, .06, .38$, and .00 for generous, warm, intelligent, and submissive respectively, with the indicated order corresponding to dominance rank found by Hays (1958). Thus, the observed asymmetries

Table 2

Contingency Table for Relationship between First Question Response [p(A|B)] and Second Question Response $[p(B \mid A)]$ for Trait Pair Comparisons

\begin{tabular}{cccc}
\hline & \multicolumn{3}{c}{ Second Question Response } \\
\cline { 2 - 4 } First Question Response & $\mathrm{p}(\mathrm{B} \mid \mathrm{A})<\mathrm{p}(\mathrm{B})$ & $\mathrm{p}(\mathrm{B} \mid \mathrm{A})=\mathrm{p}(\mathrm{B})$ & $\mathrm{p}(\mathrm{B} \mid \mathrm{A})>\mathrm{p}(\mathrm{B})$ \\
\hline $\mathrm{p}(\mathrm{A} \mid \mathrm{B})<\mathrm{p}(\mathrm{A})$ & $17^{*}$ & 5 & 0 \\
$\mathrm{p}(\mathrm{A} \mid \mathrm{B})=\mathrm{p}(\mathrm{A})$ & 11 & 118 & 6 \\
$\mathrm{p}(\mathrm{A} \mid \mathrm{B})>\mathrm{p}(\mathrm{A})$ & 1 & 24 & 42 \\
\hline
\end{tabular}

*Frequencies shown. $N=224$. 
were roughly related to scaled implicational dominance values.

\section{DISCUSSION}

Subjects revealed a clear correlational structure in their assessments of conditional probabilities. The relationships were in general accord with mutual dependencies required by probability and may well have reflected perceptions based on experience. Such would be the case when judgmental heuristics are applied. However, the strategies applied were not dependent on the use of concepts of probability, as is demonstrated by the $21 \%$ rate of asymmetries of conditional probabilities in pair judgments. Such might also be true if judgmental heuristics are applied.

The data do not provide a clear guide to the nature of heuristics used, although results suggest some possibilities. For example, the asymmetries in the liberal-social worker pairs may have reflected the fact that the social worker category is smaller and more homogeneous than the liberal category. Hence, the set of characteristics overlapping the two categories may have comprised a relatively large proportion of the characteristics of the social worker category. Thus, "social worker" might be viewed as strongly implying "liberal." Such would not be the case for the converse, because the liberal category is larger and more heterogeneous. The outcome thus could emanate from a process akin to similarity judgment based on common and distinctive features proposed by Tversky (1977).
It is also possible that confusions of causality with correlation could account for perceptions of unidirectional dependencies. For example, would generosity more likely be perceived as leading to warmth than would the converse? Understanding the nature of heuristics used awaits detailed investigations of the comparison process.

\section{REFERENCES}

HaYs, W. L. (1958). An approach to the study of trait implication and trait similarity. In R. Tagiuri \& L. Petrullo (Eds.), Person Perception and Interpersonal Behavior (pp. 289-299). Stanford, California: Stanford University Press.

SHWEDER, R. A. (1977). Likeness and likelihood in everyday thought: Magical thinking and everyday judgments about personality. In P. N. Johnson-Laird and P. C. Wason (Eds.), Thinking: Readings in Cognitive Science (pp. 446-467). Cambridge, New York: Cambridge University Press.

TVersky, A. (1977). Features of similarity. Psychological Review, 84, 327-352.

Tversky, A., \& Kahneman, D. (1973). Availability: A heuristic for judging frequency and probability. Cognitive Psychology, 5, 207-232.

Tversky, A., \& Kahneman, D. (1983). Extensional versus intuitive reasoning: The conjunction fallacy in probability judgment. Psychological Review, 90, 293-315.

(Manuscript received for publication August 19, 1985.) 